\title{
Evaluation and Treatment of Low Back Pain in Family Practice
}

\author{
Peter A. Rives, MD, and Alan B. Douglass, $M D$
}

\begin{abstract}
Almost all working adults, more than half in any given year, experience low back pain. Although the differential diagnosis is extensive, most symptoms have biomechanical causes and resolve promptly with little intervention, although recurrence is common. History and physical examination are important in distinguishing potential causes and identifying "red flags" for more serious conditions. Diagnostic imaging should be ordered only when necessary because of the high incidence of radiologic abnormalities in asymptomatic persons. Once serious illness is ruled unlikely, first-line drug therapy with acetaminophen, a cyclo-oxygenase- 2 inhibitor or a nonsteroidal anti-inflammatory drug is recommended. Shortterm use of muscle relaxants may be considered, but they can be sedating. Patients should stay as active as possible. Comorbid conditions such as sleep disorders, anxiety, or depression should be treated, and psychosocial issues should be addressed. Opioids should be prescribed if other treatments have been insufficiently effective and if there is evidence of improved function with opioid treatment that outweighs adverse effects. Adjuvant antidepressants and anticonvulsants should be considered, especially in chronic or neuropathic pain. If a structural defect is identified and a diagnostic or therapeutic procedure is available, consider referral. If symptoms have not improved within 4 to 6 weeks, re-evaluation and additional diagnostic workup should be considered. (J Am Board Fam Pract 2004;17:S23-31.)
\end{abstract}

Low back pain is nearly ubiquitous in American society. It is frequently treated by family physicians and is the fifth most common reason for all physician visits. ${ }^{1}$ It is also a leading cause of lost work time and disability, responsible for direct health care expenditures of more than $\$ 20$ billion annually. ${ }^{2}$

Many published guidelines for the diagnosis and management of low back pain are available. Most are straightforward, but few emphasize what family physicians actually do in practice, and they lack the richness that comes from also addressing the psychosocial issues, ${ }^{3}$ such as economic factors, averse incentives, cultural expectations, and personal reactions, that usually surround this problem.

From the Pain Care Institute, Owensboro, KY (PAR), and Family Practice Residency Program, Middlesex Hospital, Middletown, CT (ABD). Address correspondence to Peter A. Rives, MD, FAAFP, 2350 Heartland Park, Owensboro, KY 42303 (e-mail: prives@adelphia.net).

The Family Practice Pain Education Project (FP-PEP) acknowledges an unrestricted educational grant from Pfizer to Cardinal Health to produce educational materials for primary care doctors about pain management. The information provided here is the opinions and research of the family physicians who served on FP-PEP.

This work was presented in part at the 2003 American Academy of Family Physicians (AAFP) Scientific Symposium.

\section{Definitions}

Low back pain can be broadly categorized into 5 clusters, including: (1) uncomplicated low back pain (nonradiating with no structural damage or defect), (2) uncomplicated sciatica (radiating back pain that does not extend below the knee), (3) major neurologic dysfunction (loss of motor function or continence), (4) major mechanical problem (spinal fracture or instability), and (5) infection or neoplasm. These categories drive the initial portions of the management algorithm (Figure 1). Many authors also divide low back pain into acute and chronic. ${ }^{4}$

Although not always immediately apparent or easily determined, it is believed that most patients with low back pain have an underlying anatomic pain generator driving the symptoms. ${ }^{5}$ Potential pain generators include myofascial tissues, facet (zygapophysial) joints, discs, nerves, ligaments, and bony structures.

\section{Prevalence and Natural History}

Back pain is the most frequent cause of activity limitation in people aged younger than 45 years. Approximately $90 \%$ of all people experience low back pain at some time, ${ }^{6}$ and up to $50 \%$ of working adults have back pain each year. ${ }^{7}$ 


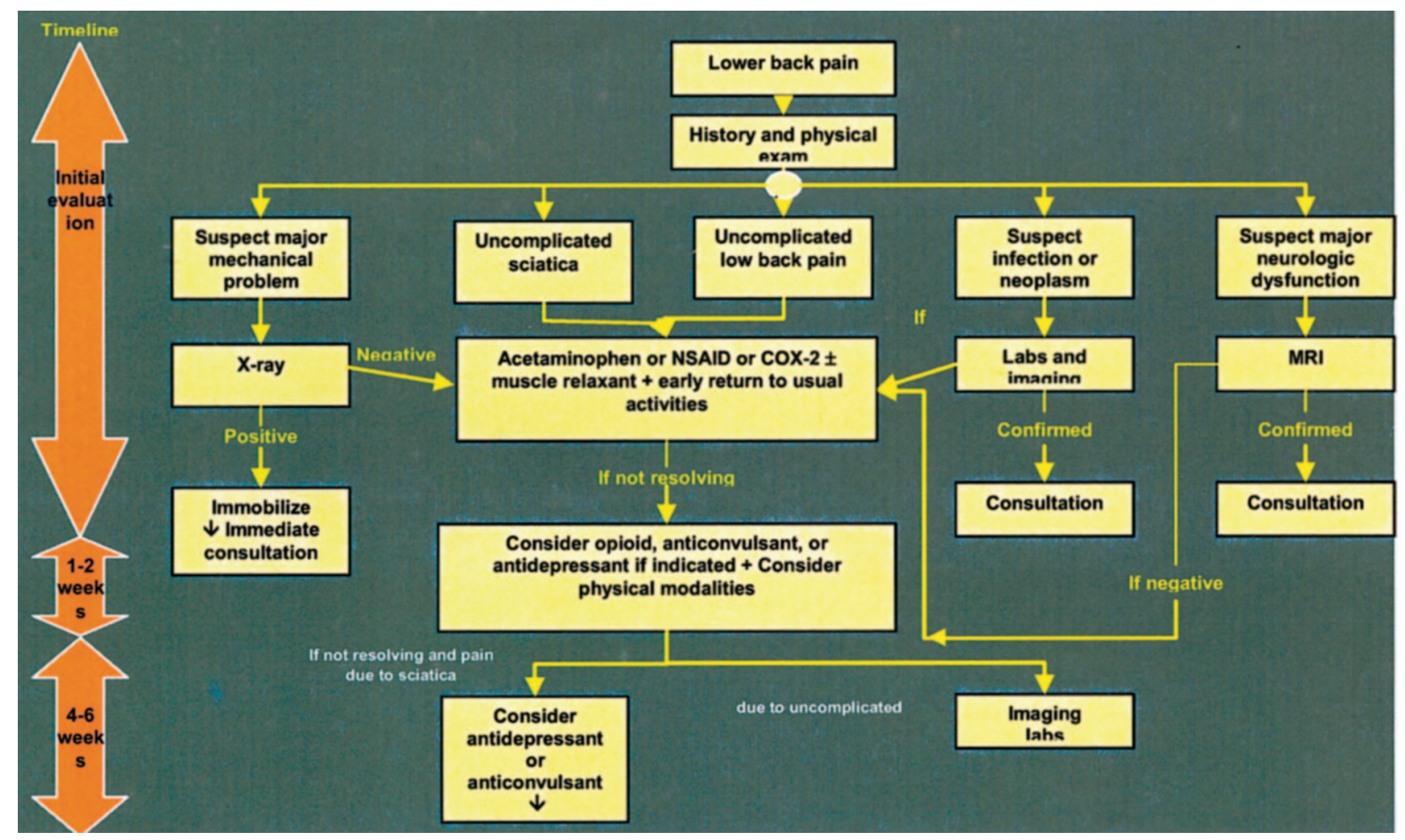

Figure 1. Algorithm for evaluation and management of low back pain.

Most patients who miss work because of back pain return within 3 months. On average, $60 \%$ to $70 \%$ recover by 6 weeks and $80 \%$ to $90 \%$ by 12 weeks. After 12 weeks, further recovery is slow. Lifetime recurrence rates of as high as $85 \%$ have been documented. ${ }^{8}$ Reported rates of low back pain are generally higher for white persons than for other racial groups. ${ }^{8}$ Biopsychosocial factors such as presence of depression symptoms, previous history of back trouble, ${ }^{9}$ reimbursement issues, and ongoing litigation affect recovery and prognosis. When a public insurance system eliminated compensation for pain and suffering, the incidence of claims decreased by $31 \%$. Improvements in pain and physical functioning and the absence of depressive symptoms correlated with faster claim closure. High pain intensity, female gender, full-time employment, concentration problems, and lawyer involvement early in the claim process delayed claim closure. ${ }^{10}$

Each year, about 2\% of the American workforce have back injuries covered by workman's compensation. The total annual direct cost of treating this subgroup was estimated to be $\$ 11.4$ billion in 1994. ${ }^{6,11}$ Low back pain accounted for 23\% (\$8.8 billion) of total workers' compensation payments in $1995 .^{12}$

\section{Differential Diagnosis}

Low back pain has many causes. An exact diagnosis and anatomic pain generator may not always be evident, especially at the first visit. It is important to consider all possible causes (Table 1). It has been postulated that a pain-spasm cycle may exist in low back pain. ${ }^{13}$ Whether this is a protective muscle spasm indicating pathology in a neighboring joint has yet to be elucidated. ${ }^{14}$ Myofascial trigger points commonly occur, and bony and ischemic pain may contribute to symptoms. Bulging intervertebral discs and osteophytes may impinge on a nerve root, causing pain and dysesthesia. Pain can also be referred from more distant sources, including visceral organs, including abdominal aortic aneurysm or renal stones.

Nonorganic low back pain also occurs and can be divided into several categories, including (1) psychosomatic spinal pain (tension syndromefibrositis, or muscle tension generated physiologically by anxiety), (2) psychogenic spinal pain (somatization of anxiety into neck or back pain with no physiologic changes, as in a conversion reaction), (3) psychogenic modification of organic spinal pain (an emotional reaction that modifies the appreciation of an organic pain), and (4) situational spinal 
Table 1. Differential Diagnosis of Low Back Pain

\begin{tabular}{l} 
Uncomplicated low back pain \\
Disc degeneration \\
Uncomplicated sciatica \\
Myofascial pain \\
Fracture \\
Spinal stenosis \\
Spinal instability \\
Facet arthropathy \\
Infection \\
Neoplasms \\
Referred pain \\
Ischemia \\
Visceral organ pain \\
Congenital deformity \\
Neuropathic pain \\
Peripheral \\
Central \\
Complex regional pain syndrome \\
Fibromyalgia \\
Psychogenic pain \\
Litigation-associated pain \\
Exaggeration reaction \\
Somatization disorders \\
Pseudoaddiction \\
Drug diversion \\
\hline
\end{tabular}

pain (litigation reaction, conscious overconcern or exaggeration). ${ }^{15}$

A number of metabolic disorders can contribute to neuropathy, fracture, muscle tension, or associated depression/anxiety. These include electrolyte disorders, diabetes, thyroid, renal, and liver disease.

\section{Current Standards of Care}

A number of guidelines exist for the evaluation of patients with low back pain. The most prominent include those from the Institute for Clinical Systems Improvement, ${ }^{16}$ the Royal College of General Practitioners ${ }^{17}$ and the US Veterans Administration. $^{18}$

\section{Evaluation of the Patient with a Diagnosis of Low Back Pain}

The goal of diagnosis is to define the anatomic pain generator(s) as specifically as possible, recognizing that this is not always possible. Physicians should be aware that some patient presentations can be "diagnostic traps," leading down an unhelpful treatment path. ${ }^{15}$ For example, pain from a facet joint can radiate down the leg and be incorrectly diagnosed as disk herniation. Other pathological conditions may become evident with time, such as the
Table 2. Important Historical Factors in Evaluation of Patients with Low Back Pain

Mechanism of onset

Location of symptoms

Duration of pain

Character of pain

Neurologic

Constitutional

Behavioral

Medical illness

Prior surgery/back pain

Lifestyle/trauma

Legal/disability issues

Pharmacologic

Systems review

classic osteoporotic vertebral collapse that later is discovered to be caused by a metastatic lesion. Frequent and careful reevaluation is therefore vital, and failure to improve should prompt reassessment. On the other hand, if pain does not fit any known syndrome's diagnostic profile, there may be other factors involved that interfere with diagnosis and/or recovery and need to be addressed. ${ }^{19}$

\section{History}

History taking must be approached in a careful, consistent manner. Key historical areas to be covered are summarized in Table 2. Physicians should specifically ask about prior treatments for low back pain and their effectiveness. Accurately assessing patients' problems and expectations is a key to successful therapy.

Physicians should constantly be alert for "red flags" and "yellow flags." Red flags denote symptoms or physical findings suggestive of a potentially serious cause for pain that requires immediate evaluation. ${ }^{20}$ Examples include a history of progressive physical deficit, fever, pain at rest or at morning awakening without relief, distal numbness or weakness, or loss of bowel or bladder control with saddle anesthesia. High impact trauma is a risk factor for serious fractures and misalignments. Weight loss, fatigue, insomnia, and night pain can indicate malignancy with metastases to bone or chronic infection such as osteomyelitis. Spinal osteomyelitis can present with back pain, fever, ${ }^{21}$ and night sweats. ${ }^{22}$ In young patients with back pain, ankylosing spondylitis, spondylosis, and spondylolisthesis should be considered. A personal history of cancer, immune 
system deficiency, or the use of immunosuppressive medications such as corticosteroids increases the likelihood of a serious cause for the back pain.

Yellow flags denote adverse prognostic indicators. $^{23}$ Examples include depressive symptoms, work-related injuries still in litigation, signs and symptoms not consistent with pain severity, and behaviors incongruent with underlying anatomic and physiologic principles. Yellow flags signal the potential need for more intensive and complex treatment and/or earlier specialist referral. Emotional stress has long been recognized as a contributor to pain and/or its perception. ${ }^{24-26}$ When yellow flags are present, clinicians need to be vigilant for deviations from the normal course of illness.

Physicians should be alert for signs of drug addiction or diversion in patients seeking pain medications. Worrisome behaviors include a history of known substance abuse, visits to multiple physicians, requests for specific medication(s), lost prescriptions, and multiple failed therapies. Inconsistent responses to dosage changes or patient resistance to switching to an approximately equipotent opioid are of concern.

\section{Physical Examination}

The physical examination should dovetail with the history to generate a working differential diagnosis. Key portions of the examination are summarized in Table 3. Examination should seek identifiable patterns of findings suggestive of a diagnosis as well as potential sources of referred pain. Skin examination may reveal an infection such as zoster or cancer. Palpation may reveal crepitus suggestive of fracture (often with severe point tenderness over bone), instability, myositis, myofascial trigger points, or visceral organ tenderness. Range of motion assessment may reveal functional deficits. Pain on upper body flexion and rotation can indicate facet arthropathy or other structural problems. Rectal examination can reveal prostatitis, sacral pathology, or colon cancer.

During neurologic examination (Table 4), vibratory deficit may indicate a neuropathic process. Dermatomal distribution (Figure 2) of pain suggests nerve impingement. Muscle weakness may also show a pattern indicating nerve impingement or, if diffuse, metabolic or central nervous system disease. Cerebellar signs and gait disturbances are important to any disability determination. Straight leg raise can reveal radiculopathy. Crossed nerve
Table 3. Important Components of the Physical Examination in the Evaluation of Low Back Pain

Inspection

Muscle symmetry

Skin

Palpation

Bone

Spinous process

Sacroiliac joint

Hip and pelvis

Muscles

Trigger points

Range of motion

Axial load

Extension with rotation

Special tests

Abdomen

Rectal exam

Pelvic exam

stretch can indicate peripheral nerve impingement. $^{27}$

Waddell signs for nonorganic pain ${ }^{28}$ have been proposed to indicate a nonorganic pathogenesis of back pain. Signs include superficial nonanatomic tenderness, pain from simulation maneuvers that should not elicit pain, distraction maneuvers that should elicit pain but do not, regional disturbances not consistent with known patterns of pain, and over-reaction during examination. It is theorized that a greater number of signs present indicate a higher likelihood that a nonorganic cause of back pain is present. However, Waddell signs do not definitively rule out the possibility of organic disease. In a study of acute back pain in an occupational setting, patients with Waddell signs took a significantly longer time to return to unrestricted, regular work and used physical therapy and lumbar computerized tomographic imaging more frequently. $^{29}$

Table 4. Important Components of the Neurologic Examination in the Evaluation of Low Back Pain

Sensory exam

Touch

Attention to dermatomes

Motor exam

Strength

Gait (heel/toe)

Muscle tone/bulk

Posture/stance

Deep tendon reflexes

Special tests

Dural signs

Straight leg raise

Crossed straight leg raise

Waddell signs 


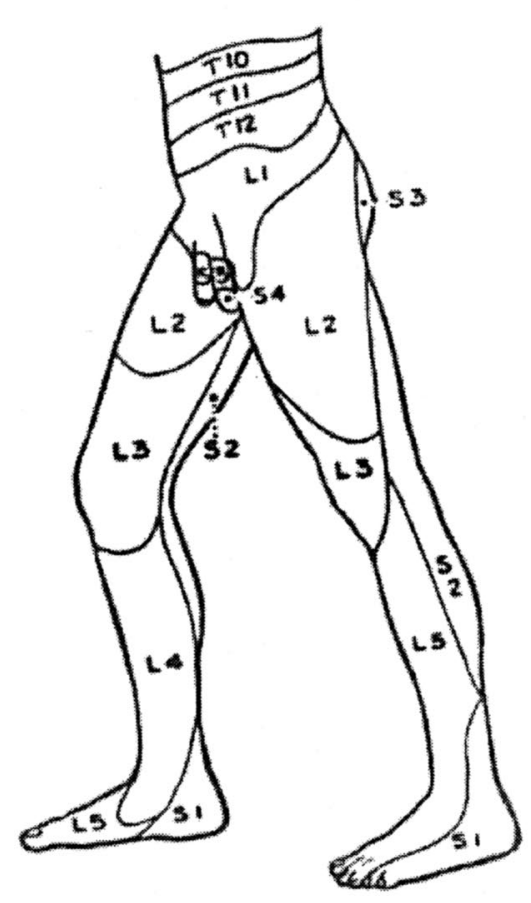

Figure 2. Sensory dermatomes of the lower extremities.

\section{Diagnostic Imaging and Testing}

One goal of evaluation is to minimize unnecessary imaging studies that may generate potentially misleading information. Diagnosis can be confused by the high incidence of radiographic abnormalities in asymptomatic persons. On X-rays, $79 \%$ of patients between 50 and 65 years of age have narrowing, sclerosis, or osteophytes, and on magnetic resonance imaging (MRI), 14\% of patients aged younger than 40 years and $28 \%$ of patients aged older than 40 years have major abnormalities. ${ }^{30}$ The majority of asymptomatic abnormalities on MRI are bulges and protrusions but not extrusions. ${ }^{31}$ Imaging studies should be ordered in patients with progressive neurologic deficits, failure to improve, history of trauma, and those at elevated risk for malignancy or infection. ${ }^{32}$

Several diagnostic tests can help diagnose malignancy or infection in patients with back pain. ${ }^{33}$ Serum or urine protein electrophoresis is the best initial diagnostic test for multiple myeloma given that many patients will have a normal bone scan. ${ }^{34}$ A history suspicious for vertebral cancer combined with an elevated erythrocyte sedimentation rate

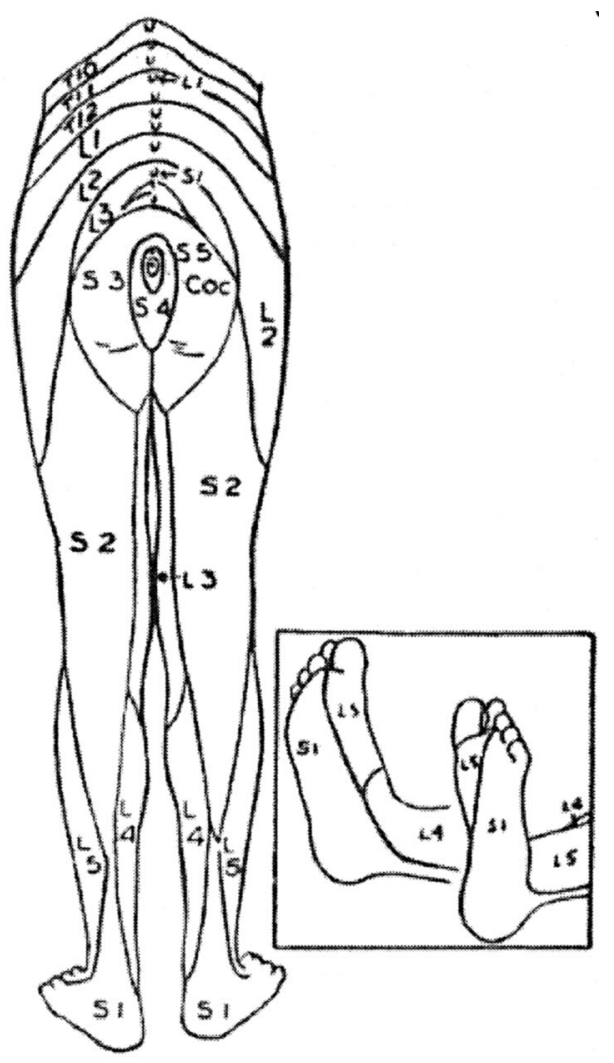

(ESR) has a positive correlation for vertebral cancer. ${ }^{35}$ However, the overall prevalence of malignancy in a study of hospitalized patients with an elevated ESR was only slightly higher (25\%) than the prevalence in patients with a normal ESR $(15 \%) .{ }^{36}$ Fever, elevated sedimentation rate, leukocytosis, and elevations in C-reactive protein level can all be indicative of infection. Blood cultures demonstrate bacteremia in up to $72 \%$ of cases of acute osteomyelitis. ${ }^{37,38} \mathrm{MRI}$ is the most sensitive and specific test in identifying spinal infection. ${ }^{39}$

\section{Management of the Patient with Low Back Pain}

Once patients have been classified into a general category of back pain, management should follow the outline in Figure 1. "Red flag" conditions should be managed expeditiously and may require prompt specialist referral.

\section{Drug Therapy}

Most patients will have tried over-the-counter back pain remedies before seeking physician consul- 
tation. Initial therapy with acetaminophen, an nonsteroidal anti-inflammatory drug, or a cyclooxygenase-2-specific inhibitor is recommended (strength of recommendation A). ${ }^{40}$ Muscle relaxants can be effective when there is significant muscle spasm present, but benefits must be balanced with their sedative properties (strength of recommendation B). ${ }^{41,42}$ Tramadol can be an effective analgesic and has mild selective serotonin reuptake inhibitor properties, but side effects are common. ${ }^{43-46}$ An extensive body of evidence supports the effectiveness of short-acting opioids for moderate to severe pain (strength of recommendation A). ${ }^{47}$ Long-acting opioids are appropriate when other treatment modalities have been inadequate and the demonstrated improvement in functionality with the opioid therapy outweighs side effects. ${ }^{48}$ If pain is not responsive to opioid therapy or functionality does not improve, then the opioid should be discontinued. Adjuvant tricyclic antidepressants and anticonvulsants are effective in patients with underlying depression or a neuropathic component to their pain (strength of recommendation B). ${ }^{48}$ Amitriptyline has been most extensively studied in neuropathic pain, but its risks of sedation, anticholinergic side effects, and falls in elderly patients is higher than other agents within the class. ${ }^{49}$ Epidural corticosteroid injections are indicated only for radiculopathy (strength of recommendation B). ${ }^{50,51}$

\section{Physical Modalities}

After making an initial determination that a patient's back pain is uncomplicated, physical modalities should be emphasized. Stretching, ice, and heat are all effective (strength of recommendation B). ${ }^{52-54}$ Although there is no definitive evidence supporting the effectiveness of massage, many patients find it helpful. There is limited evidence of the short-term effectiveness of manipulation (strength of recommendation B). After 6 weeks, all approaches seem to have about the same rates of success. ${ }^{55}$

Bed rest should be avoided, except possibly for the first 24 hours (strength of recommendation A). ${ }^{56,57}$ Patients should be encouraged to return to work and their usual activities as soon as possible (strength of recommendation A). ${ }^{58}$ Patients should be educated in proper posture, sitting position, and lifting techniques.

Beyond the acute phase, the choice of physical modalities is usually patient-specific, given the dearth of high-quality evidence supporting most interventions. ${ }^{58}$ Potentially beneficial therapies include exercise rehabilitation programs, ${ }^{59}$ electrical muscle stimulation, ${ }^{60}$ work hardening programs, and acupuncture. ${ }^{61}$ Transcutaneous electrical nerve stimulation (TENS) has not been shown to be effective for low back pain. ${ }^{62}$

\section{Other Therapies}

In appropriate clinical settings and selected patients, support groups, counseling, addiction therapy, or relaxation therapy can all improve outcomes. ${ }^{63}$ Treatment of coincident depression and anxiety can improve pain control. ${ }^{64}$ Some alternative treatments may potentially be of benefit, although firm evidence of efficacy is not currently available. $^{65}$

\section{Interventional Pain Management}

Interventional pain specialists offer a variety of diagnostic and therapeutic options that may be helpful in the care of some patients. These include diagnostic facet and nerve blocks, therapeutic rhizotomies and nerve ablations, selective joint injections, epidural injections, intradiscal distraction therapy, and spinal endoscopy. Epidural steroids have been shown to be effective for pain with a significant inflammatory component, including nerve irritation or impingement. ${ }^{63}$ (strength of recommendation B) Referral to an interventionist is appropriate if a structural defect is likely and a procedure may help. Good communication between the family physician and interventionist is critical for the success of these procedures.

\section{Confounding Factors in the Evaluation and Management of Low Back Pain}

There are many potentially confounding variables ("yellow flags") in the diagnosis and treatment of low back pain. It is common for patients to have a hidden agenda or set of beliefs that is not obvious to the physician. These may have an adverse effect on the outcome of treatment.

Certain beliefs and behavioral or cultural factors may consistently predict poor outcomes. These include: ${ }^{17}$

- A belief that back pain is harmful or potentially severely disabling 
- fear-avoidance behavior and reduced activity levels

- a tendency to depressed mood and withdrawal from social interaction

- an expectation of passive treatment(s), rather than a belief that active participation will help

- other factors that may interfere with recovery (anxiety, depression, unresolved occupational issues, prior disability claims).

Affective disorders are very common confounding factors in patients with chronic pain. Their concomitant treatment may improve outcomes. ${ }^{64}$

Opioid or benzodiazepine addiction and prescription drug diversion among patients with back pain can be very challenging. "Pseudoaddiction" is a patient behavior pattern often caused by undertreatment of pain. The patient initially seems to be drug seeking, but normal behavior returns with appropriate pain management.

Fibromyalgia and other complex pain syndromes often have low back pain as one of their symptoms. Their management is complex and beyond the scope of this article.

Conscious or unconscious secondary gain in a patient's illness portends a poor outcome. Workrelated back injuries and cases in which litigation is pending carry particular risk. Patient orientation toward treatment and improvement may determine the extent to which back pain responds to any therapy. The family physician has unique expertise in caring for undifferentiated problems, often in patients from different cultural backgrounds and value systems. Good communication and empathic understanding can enable the patient and encourage them to participate in their care. ${ }^{66}$ Familiarity with the patient and family can generate trust, encourage compliance, and uncover hidden agendas in patients with chronic back pain.

Lifestyle factors can be part of the original cause of the back problem and should be appropriately modified. Cultural factors and patient belief systems and values all affect openness to and response to therapy and should always be considered when developing a therapeutic plan.

\section{Conclusions}

Low back pain is extremely common. The most appropriate diagnostic approach is to look for specific biomechanical causes and identify potential anatomic pain generator(s) when possible. Most symptoms resolve relatively promptly with little intervention, but recurrence is common.

Patient history and physical examination are important in distinguishing potential etiologies and immediately identifying red flags denoting more serious conditions, as well as yellow flags that may confound both diagnosis and prognosis. Findings should be consistent with known pathologic processes. Pain that is inconsistent with known patterns of disease represents an important yellow flag and requires careful re-evaluation. Diagnostic imaging should be ordered only when truly necessary because of the high incidence of radiologic abnormalities in asymptomatic persons.

Once serious illness is ruled unlikely, first-line drug therapy with acetaminophen, a nonsteroidal anti-inflammatory drug, or a cyclo-oxygenase-2specific inhibitor is recommended. Short-term use of muscle relaxants may be considered, but their benefits must be balanced with their sedative properties. Patients should be advised to stay as active as possible while continuing usual daily activities. In patients with complicating comorbid conditions, such as depression, appropriate therapy should be initiated. Opioids should be prescribed if other treatments have been insufficiently effective and there is demonstrated evidence of improved function that outweighs any impairment caused by adverse effects. Adjuvant antidepressants and anticonvulsants should be considered, especially in chronic or neuropathic pain and when coincident depression is suspected. If a structural defect is identified and a diagnostic or therapeutic procedure is available, referral should be considered. If symptoms have not resolved adequately within a 4- to 6-week period, reevaluation and additional diagnostic workup should be considered.

We acknowledge the contributions of the other members of the Family Practice Pain Education Project: Gail Cawkwell, MD, Alan Gibovsky, MD, Deborah Haynes, MD, Tanya Jones, MD, Laeth Nasir, MBBS, Trish Palmer, MD, Sunil Panchal, MD, Francine Rainone, MD, PhD, Knox Todd, MD, and James Toombs, MD.

\section{References}

1. Hart LG, Deyo RA, Cherkin DC. Physician office visits for low back pain. Frequency, clinical evaluation, and treatment patterns from a U.S. national survey. Spine 1995;20:11-9.

2. Deyo RA, Cherkin D, Conrad D, Volinn E. Cost, 
controversy, crisis: low back pain and the health of the public. Annu Rev Public Health 1991;12:141-56.

3. Gatchel RJ, Gardea MA. Psychosocial issues: their importance in predicting disability, response to treatment, and search for compensation. Neurol Clin 1999; 17:149-66.

4. Zarkowska E, Philips HC. Recent onset vs. persistent pain: evidence for a distinction. Pain 1986;25: 365-72.

5. Bartleson JD. Low back pain. Curr Treat Options Neurol 2001;3:159-68.

6. Frymoyer JD. Back pain and sciatica. N Engl J Med 1988;318:291-300.

7. Nachemson AL. Newest knowledge of low back pain. A critical look. Clin Orthop 1992; Jun:8-20.

8. Research on low back pain and common spinal disorders [monograph on the Internet]. Bethesda (MD): National Institutes of Health [cited 2004 Aug 23]. Available from: http://grants2.nih.gov/grants/guide/ pa-files/PA-97-058.html

9. Burton AK, Tillotson M, Main CJ, Hollis S. Psychosocial predictors of outcome in acute and subchronic low back trouble. Spine 1995;20:722-8.

10. Cassidy JD, Carroll L, Cote P, Berglund A, Nygren A. Low back pain after traffic collisions: a population-based cohort study. Spine 2003;28:1002-9.

11. Anderssen GBJ. The epidemiology of spinal disorders. In: Frymoyer JW, editor. The adult spine: principles and practice. New York: Raven Press; 1997. p. 93-141.

12. Murphy PL, Volinn E. Is occupational low back pain on the rise? Spine 1999;24:691-7.

13. van Dieen JH, Selen LP, Cholewicki J. Trunk muscle activation in low-back pain patients, an analysis of the literature. J Electromyogr Kinesiol 2003;13:33351 .

14. Maigne JY, Vautravers P. Mechanism of action of spinal manipulative therapy. Joint Bone Spine 2003; 70:336-41.

15. McCullough JA, Snook D, and Weiner BK. Differential diagnosis of low back pain. In: Tollison CD, Satterthwaite JR, Tollison J editors. Practical pain management. 3rd ed. Philadelphia: Lippincott Williams \& Wilkins; 2002. p. 389-410.

16. Thorson DC, Campbell R, Kuko O, et al. Health care guideline: adult low back pain. 9th ed. [monograph on the Internet]. Bloomington (MN): Institute Clinical Systems Improvement (ICSI); 2003 [cited 2004 Aug 23]. Available from: http://www.icsi.org/ display_file.asp?FileId $=138 \&$ title $=$ Adult $\% 20 \mathrm{Low}$ \%20Back\%20Pain

17. Clinical guidelines for the management of acute low back pain [monograph on the Internet]. London: The Royal College of General Practitioners; 2001 [cited 2004 Aug 23]. Available from: http://www.rcgp. org.uk/clinspec/guidelines/backpain/

18. Low back pain and sciatica in primary care. Clinical practice guideline [monograph on the Internet].
Washington (DC): Veterans Health Administration, Department of Veterans Affairs; 1999 [cited 2004 Aug 23]. Available from: http//www.oqp.med.va. gov/cpg/LBP/LBP_Base.htm

19. Hadjistavropoulos HD, Craig KD. Acute and chronic low back pain: cognitive, affective, and behavioral dimensions. J Consult Clin Psychol 1994; 62:341-9.

20. Greene G. 'Red flags': essential factors in recognizing serious spinal pathology. Man Ther 2001;6:253-5.

21. Fernandez M, Carrol CL, Baker CJ. Discitis and vertebral osteomyelitis in children: an 18-year review. Pediatrics 2000;105:1299-304.

22. Wurtz R, Quader Z, Simon D, Langer B. Cervical tuberculous vertebral osteomyelitis: case report and discussion of the literature. Clin Infect Dis 1993;16: 806-8.

23. Pincus T, Vlaeyen JW, Kendall NA, Von Korff MR, Kalauokalani DA, Reis S. Cognitive-behavioral therapy and psychosocial factors in low back pain: directions for the future. Spine 2002;27:E133-8.

24. Macfarlane TV, Kincey J, Worthington HV. The association between psychological factors and orofacial pain: a community-based study. Eur J Pain 2002; 6:427-34.

25. Rotheram-Borus MJ. Variations in perceived pain associated with emotional distress and social identity in AIDS. AIDS Patient Care STDS 2000;14:659-65.

26. Haufler AJ, Feuerstein M, Huang GD. Job stress, upper extremity pain and functional limitations in symptomatic computer users. Am J Ind Med 2000; 38:507-15.

27. Hudgins WR. The crossed straight leg raising test: a diagnostic sign of herniated disc. J Occup Med 1979; 21:407-8.

28. Waddell G, McCulloch JA, Kummel E, Venner RM. Nonorganic physical signs in low-back pain. Spine 1980;5:117-25.

29. Gaines WG Jr., Hegmann KT. Effectiveness of Waddell's nonorganic signs in predicting a delayed return to regular work in patients experiencing acute occupational low back pain. Spine 1999;24:396-400; discussion 401.

30. Boden SD, Davis DO, Dina TS, Patronas NJ, Wiesel SW. Abnormal magnetic-resonance scans of the lumbar spine in asymptomatic subjects. A prospective investigation. J Bone Joint Surg Am 1990;72:403-8.

31. Jensen MC, Brant-Zawadzki MN, Obuchowski N, Modic MT, Malkasian D, Ross JS. Magnetic resonance imaging of the lumbar spine in people without back pain. N Engl J Med 1994;331:69-73.

32. Staiger TO, Paauw DS, Deyo RA, Jarvik JG. Imaging studies for acute low back pain: when and when not to order them. Postgrad Med 1999;105:161-76.

33. Deyo RA, Diehl AK. Cancer as a cause of back pain: frequency, clinical presentation, and diagnostic strategies. J Gen Intern Med 1988;3:230-8.

34. Boccadoro M, Pileri A. Diagnosis, prognosis, and 
standard treatment of multiple myeloma. Hematol Oncol Clin North Am 1997;11:111-31.

35. van den Hoogen HM, Koes BW, van Eijk JT, Bouter LM. On the accuracy of history, physical examination, and erythrocyte sedimentation rate in diagnosing low back pain in general practice: a criteria-based review of the literature. Spine 1995;20:318-27.

36. Monig H, Marquardt D, Arendt T, Kloehn S. Limited value of elevated erythrocyte sedimentation rate as an indicator of malignancy. Fam Pract 2002;19: $436-8$.

37. Lurie JD, Gerber PD, Sox HC. A pain in the back. N Engl J Med 2000;343:723-6.

38. Nolla JM, Ariza J, Gomez-Vaquero C, et al. Spontaneous pyogenic vertebral osteomyelitis in nondrug users. Semin Arthritis Rheum 2002;31:271-8.

39. Meyers SP, Wiener SN. Diagnosis of hematogenous pyogenic vertebral osteomyelitis by magnetic resonance imaging. Arch Intern Med 1991;151:683-7.

40. Portenoy RK. Current pharmacotherapy of chronic pain. J Pain Symptom Manage 2000;19(1 Suppl): S16-20.

41. Deyo RA. Drug therapy for back pain: which drugs help which patients? Spine 1996;24:2840-50.

42. Browning R, Jackson JL, O'Malley PG. Cyclobenzaprine and back pain: a meta-analysis. Arch Intern Med 2001;161:1613-20.

43. Schnitzer TJ. Non-NSAID pharmacologic treatment options for the management of chronic pain. Am J Med 1998;105:45S-52S.

44. Aronson MD. Nonsteroidal anti-inflammatory drugs, traditional opioids, and tramadol: contrasting therapies for the treatment of chronic pain. Clin Ther 1997;19:420-32; discussion 367-8.

45. Raffa RB. Pharmacology of oral combination analgesics: rational therapy for pain. J Clin Pharm Ther 2001;26:257-64.

46. Nicholson B. Responsible prescribing of opioids for the management of chronic pain. Drugs 2003;63: 17-32.

47. Jamison RN, Raymond SA, Slawsby EA, Nedeljkovic SS, Katz NP. Opioid therapy for chronic noncancer back pain: a randomized prospective study. Spine 1998;23:2591-600.

48. American Pain Society. Principles of analgesic use in the treatment of acute pain and cancer pain. 4th ed. Glenview (IL): American Pain Society; 1999.

49. Beers MH. Explicit criteria for determining potentially inappropriate medication use by the elderly. An update. Arch Intern Med 1997;157:1531-6.

50. Slipman CW, Chow DW. Therapeutic spinal corticosteroid injections for the management of radiculopathies. Phys Med Rehabil Clin N Am 2002;13: 697-711.

51. Carette S, Leclaire R, Marcoux S, et al. Epidural corticosteroid injections for sciatica due to herniated nucleus pulposus. N Engl J Med 1997;336:1634-40.
52. Seaman DR, Cleveland C 3rd. Spinal pain syndromes: nociceptive, neuropathic, and psychologic mechanisms. J Manipulative Physiol Ther 1999;22: 458-72.

53. Nadler SF, Steiner DJ, Erasala GN, Hengehold DA, Abeln SB, Weingand KW. Continuous low-level heatwrap therapy for treating acute nonspecific low back pain. Arch Phys Med Rehabil 2003;84:329-34.

54. Constant F, Collin JF, Guillemin F, Boulange M. Effectiveness of spa therapy in chronic low back pain: a randomized clinical trial. J Rheumatol 1995; 22:1315-20.

55. Cherkin DC, Deyo RA, Battié M, Street J, Barlow $W$. A comparison of physical therapy, chiropractic manipulation, and provision of an educational booklet for the treatment of patients with low back pain. N Engl J Med 1998;339:1021-9.

56. Hagen KB, Hilde G, Jamtvedt G, Winnem MF. The Cochrane review of bed rest for acute low back pain and sciatica. Spine 2000;25:2932-9.

57. Malmivaara A, Hakkinen U, Aro T, et al. The treatment of acute low back pain-bed rest, exercises, or ordinary activity? N Engl J Med 1995;332:351-5.

58. Harris GR, Susman JL. Managing musculoskeletal complaints with rehabilitation therapy: summary of the Philadelphia Panel evidence-based clinical practice guidelines on musculoskeletal rehabilitation interventions. J Fam Pract 2002;51:1042-6.

59. Faas A. Exercises; which ones are worth trying, for which patients and when? Spine 1996;21:2874-7.

60. Glaser JA, Baltz MA, Nietert PJ, Bensen CV. Electrical muscle stimulation as an adjunct to exercise therapy in the treatment of nonacute low back pain: a randomized trial. J Pain 2001;2:295-300.

61. Meng CF, Wang D, Ngeow J, Lao L, Peterson M, Paget S. Acupuncture for chronic low back pain in older patients: a randomized, controlled trial. Rheumatology (Oxford) 2003;42:1508-17.

62. Deyo RA, Walsh NE, Martin DC, Schoenfeld LS, Ramamurthy S. A controlled trial of transcutaneous electrical nerve stimulation (TENS) and exercise for chronic low back pain. N Engl J Med 1990;322: 1627-34.

63. Cohen JE, Goel V, Frank JW, Bombardier C, Peloso P, Guillemin F. Group interventions for people with low back pain: an overview of the literature. Spine 1994;19:1214-22.

64. Atkinson JH, Slater MA, Wahlgren DR, et al. Effects of noradrenergic and serotonergic antidepressants on chronic low back pain intensity. Pain 1999;83: 137-45.

65. Berman BM, Jonas W, Swyers JP. Issues in the use of complementary/alternative medical therapies for low back pain. Phys Med Rehabil Clin N Am 1998;9: 497-513.

66. Phillips WR, Haynes DG. The domain of family practice: scope, role, and function Fam Med 2001; $33: 273-7.66$ 